\title{
Reflections on David Clarke's intellectual legacy
}

\author{
Alan Schoenfeld ${ }^{1}$ (1) \\ Accepted: 30 June 2021 / Published online: 19 July 2021 \\ (c) FIZ Karlsruhe 2021
}

I find myself challenged in thinking about how to write about someone like David Clarke, because there is so much that is personal as well as intellectual—indeed, in David's case, it is impossible to separate the two. Of all my colleagues, David may have been the warmest and most generous. His life, at least in my experience, was about sharing the pleasures and passions of experience, be they personal or professional. Who else would make you feel like a member of the family at family gatherings? Who else would host dinner after dinner at meetings around the world, bringing together a collection of scholars whose thinking would (sometimes subtly, sometimes not so subtly) advance your own? Who else, whenever and wherever we met, would take a little gift for your daughter out of his backpack? I can't remember a single event with David that wasn't just plain fun. At the same time, I can't remember a single event with David that didn't, at some point, grapple with fundamental issues. They might have been about teaching, they might have been about learning, they might have been meta at some levelfor example I remember David whispering to me at a symposium, "There are too many of us old White guys at the podium. We can't let this happen again." Concern for others, pleasure in their company, and pleasure in their ideas, were all wrapped together.

Even a synoptic account of David's contributions would be a challenge. I stopped counting the papers in his list of publications (see Clarke, 2020, https://internationalcentref orclassroomresearch.wordpress.com/djclarke-publications/) when I neared 200 and the end was not yet in sight, and I marveled at the scope of the collaborations they represented. Instead, I'll focus on a few key ideas.

An enduring mark of an idea's profundity is that once you've made sense of it, it seems so natural that you can't imagine ever having thought otherwise- even though the

Alan Schoenfeld

alans@berkeley.edu

1 University of California, Berkeley, USA idea wasn't part of the field's discourse not that long ago. That is the nature of David's big ideas.

Consider, for example, the core ideas behind the International Classroom Lexicon Project (Clarke et al., 2017). On the one hand, cross-cultural studies have been around for some time. When I began my problem solving work I sought out problems from around the world, hoping to find mathematical riches. I did, for sure-the Russian and Hungarian problem solving books contained wonderful mathematical problems. And, when I discovered that some of these interesting and challenging problems were part of the regular curricula in some countries, I stumbled into the realization that many of my tacit assumptions about teaching were wrong. Over time it became clear that much of what I believed was natural, and what I thought was possible, was in fact the abstraction of my experiences in the U.S. system. There was a larger world out there, and a great deal to be learned from it.

It's one thing to recognize this; it's quite another thing to turn that kind of recognition into an art form, a life-long project, and a source of revelatory ideas. That's what David did. I'll tell two stories. The first occurred at least twenty years ago, when David was telling me about his detailed examinations of lesson study. Do you know, he said, that in lesson study there is a technical term, Kikan-Shido, that describes "between desks instruction"- the kind of events and interactions that take place while a teacher circulates through the classroom as the students are engaged, individually or in small groups, in working problems or exercises?

David found this fascinating, in part, because there was no English language analogue for the term. You don't have to subscribe to the Whorfian hypothesis in its strong form to see why this matters: An object or process that has a name can be a focus of attention, while one that does not is likely to be ignored. More broadly, the technical language of a profession reflects the very conceptions of the profession.

This observation was not an endpoint for David, but a beginning. In Japan, Kikan-Shido is a key instructional practice. In Australia (and the U.S.), something happens while the teacher circulates through the room while students 
work-but what it was, and what role it played, was unarticulated. And in other nations? Well, that remained to be seen. Exploring such issues would be revelatory, not just for one particular example, but for the technical lexicons of teaching.

In a sense, what I have just described echoes Ralph Waldo Emerson's statement that "everything in our world, even a drop of dew, is a microcosm of the universe." In this case teasing out classroom practices and language required multiple years, multiple collaborations, the construction of a body of technical methods, massive data gathering, and more. The point is that it takes vision-and work-to see what is reflected in the microcosm. (And a spirit of collaboration, so that colleagues enjoy being on the journey with you.) That's an illustration of how David followed through on his insights.

In reflecting on David's work, I want to highlight three points. The first is that David was a true internationalist, with a passionate interest in understanding approaches to teaching and learning around the world. This meant problematizing everything, and as much as possible, framing issues from the perspectives of others rather than assuming there was one "natural" perspective. (His formal term for this was "complementary accounts.") I remember one conversation in particular. I was telling David about my recent work, in which classroom discourse plays a fundamental role-specifically, that making student thinking public both through written work and classroom discourse is central to the Teaching for Robust Understanding (TRU) framework (2021, https://truframework.org/). Student discourse plays a role in formative assessment, for example, and in providing students opportunities to develop a sense of disciplinary agency and positive disciplinary identities. David then told me about one of his international studies, in which he had specifically asked researchers and teachers from around the world to identify tapes of highly proficient ("expert") teachers. David said that in one tape, from a country that had done quite well on international comparisons, students said a total of seven words. "Well, in fact, only one word. They said 'yes' seven times." He then went on to tell me that he had told this story to an visiting researcher from another nation, whose reaction was, "So?" In relaying this information David could have quoted Hamlet, with a slight name change: "There are more things in heaven and earth, Alan, than are dreamt of in your philosophy." Openness to a wide range of perspectives, combined with personal openness, led to extraordinary international collaborations-evidence of which permeates this volume.

The second point harks back to Emerson's microcosm. As the previous paragraph indicates, it's not just what you compare, it's how you frame the comparisons. At the micro level, words and gestures matter; At the macro level, framing matters. It's no accident that David, many years ago, chose to title a major strand of his ongoing work "the learner's perspective" study. When people think about teaching, they think about the teacher; it's easy for the learner to get lost. His choice of title restores focus and balance. At the micro level, it's not just what you look at, it's what you choose to focus on and how you choose to look at it. The devil isn't simply in the details, as they say; the devil is the details (and the toolkit to get at them). David's fascination with multiple views of learning, in fine-grained detail, may have derived from his background as a physicist—handwaving doesn't suffice, one has to try to nail things down. To study something, you have to "see" it. In physics that leads, for example, to complex equipment that helps researchers understand the properties of subatomic particles. In classrooms, that leads (if you're David Clarke) to building classrooms with instrumentation that can zero in on ephemeral classroom events in remarkably fine-grained ways. David left us before he could truly enjoy the fruits of this labor, but I have no doubt that work at the International Centre for Classroom Research at Melbourne will build on the tools and traditions he has established.

As I read over the themes discussed here, all of the ideas seem so natural. Of course it makes sense to transcend one's parochialism (even if not especially national parochialism) by doing cross-national work. Of course that means honoring complementary accounts of teaching and learning. The same is the case for attending to language in telling ways, to building the instrumentation that reveals it, and to constructing arcs of research that connect the micro to the macro. The point is that if these things seem natural to us, it's because of David's contributions. His sense of vision allowed us to see more than we would have otherwise, and the depth of his ideas resulted in his perspectives being foundational. His influence can be seen in the chapters of this volume, and will be felt throughout the field for years to come.

\section{References}

Clarke, D. (2020). List of publications. https://internationalcentreforcla ssroomresearch.wordpress.com/djclarke-publications/

Clarke, D. J., Mesiti, C., Cao, Y., \& Novotna, J. (2017). The lexicon project: examining the consequences for international comparative research of pedagogical naming systems from different cultures. In Proceedings of the congress of European research in mathematics education, Dublin, Ireland (pp. 1610-1617).

Teaching for Robust Understanding Group. (2021). Teaching for robust understanding framework. https://truframework.org/

Publisher's Note Springer Nature remains neutral with regard to jurisdictional claims in published maps and institutional affiliations. 